\title{
Mitochondriogenesis and apoptosis: possible cause of vitamin A-mediated adipose loss in WNIN/Ob-obese rats
}

Anamthathmakula Prashanth ${ }^{1}$, Shanmugam M Jeyakumar ${ }^{1}$, Lodhu Singotamu ${ }^{2}$, Nemani Harishankar ${ }^{3}$, Nappan V Giridharan ${ }^{3}$ and Ayyalasomayajula Vajreswari ${ }^{1^{*}}$

\begin{abstract}
Background: Previously, we reported that vitamin A-enriched diet (129 mg/kg diet) intake reduces the adiposity development in obese rats of WNIN/Ob strain. Here, we hypothesize that dose lesser than $129 \mathrm{mg}$ of vitamin A/kg diet would also be effective in ameliorating the development of obesity in these rats.

Methods: Five-month-old male lean and obese rats designated as A \& B were divided into four subgroups (I, II, III and IV) consisting of 8 rats from each phenotype and received diets containing $2.6 \mathrm{mg}$ (control group), $26 \mathrm{mg}, 52 \mathrm{mg}$ and $129 \mathrm{mg}$ vitamin A/kg diet as retinyl palmitate for 20 weeks. Body composition and morphological analysis of brown adipose tissue (BAT) was analyzed. Expression of uncoupling protein 1 (UCP1), retinoic acid receptor a (RARa) and retinoid $X$ receptor a (RXRa) in BAT and levels of $\mathrm{BC} 22$ and $\mathrm{Bax}$ in epididymal white adipose tissue (eWAT) were determined by immunoblotting.

Results: Vitamin A supplementation to obese rats at doses of 52 and $129 \mathrm{mg} / \mathrm{kg}$ diet showed reduced body weight gain and adiposity compared to control diet-fed obese rats receiving $2.6 \mathrm{mg}$ of vitamin A/kg diet. In BAT of obese rats, vitamin A supplementation at doses of 26 and $52 \mathrm{mg}$ of vitamin A/kg diet resulted in increased UCP1 expression with concomitant decrease in RARa and RXRa levels compared to control diet-fed obese rats. Further, transmission electron microscopy study revealed an increase in number of BAT mitochondria of obese rats supplemented with 26 and $52 \mathrm{mg}$ of vitamin A/kg diet. Also, obese rats fed on $52 \mathrm{mg} / \mathrm{kg}$ diet resulted in increased apoptosis by altering the ratio of $\mathrm{Bcl} 2 \mathrm{to}$ Bax protein levels in eWAT. Notably, most of these changes were not observed in lean rats fed vitamin A-enriched diets.

Conclusion: In conclusion, chronic consumption of $52 \mathrm{mg}$ of vitamin A/kg diet seems to be an effective dose in ameliorating obesity possibly through mitochondriogenesis, UCP1-mediated thermogenesis in BAT and apoptosis in eWAT of obese rats. Therefore, the role of dietary vitamin A in correcting human obesity would be of unquestionable relevance and can only be addressed by future studies.
\end{abstract}

Keywords: Vitamin A, Dietary supplementation, Uncoupling protein, Thermogenesis, Nuclear receptors, Adipose tissue, Apoptosis

\footnotetext{
* Correspondence: vaj_lipidresearch@yahoo.com

${ }^{1}$ Department of Lipid Biochemistry, National Institute of Nutrition (ICMR), Jamai Osmania, Hyderabad -500 007, Andhra Pradesh, India

Full list of author information is available at the end of the article
} 


\section{Background}

Obesity, an imbalanced energy metabolic disease is characterized by increased adipose tissue mass due to excessive energy accumulation in the form of triglycerides. Adipocytes accommodate the excess energy by its hyperplasic and/or hypertrophic mechanisms [1]. Though the regulation of both these process are not fully understood, adipocyte number is tightly regulated by pre-adipocyte recruitment, differentiation and by programmed cell death mechanism $[2,3]$.

Vitamin A has been shown to possess regulatory effects on energy balance and whole body adiposity $[4,5]$. Previously, we reported that chronic feeding of diet rich in vitamin A (129 mg/kg diet) for a period of 2 months decreased body weight gain and adiposity in adult male obese rats of WNIN/Ob strain [4,5]. This was majorly attributed to the activation of thermogenic pathway through up-regulation of the uncoupling protein 1 (UCP1) gene [4]. As, the dose used in previous study (though within the safe upper limit) was substantially high, here we hypothesized that chronic feeding of vitamin A-enriched diets less than $129 \mathrm{mg} / \mathrm{kg}$ diet would be effective in ameliorating the development of obesity in these rats.

\section{Methods}

\section{Animals, supplementation, and tissue collection}

The WNIN/Ob mutant strain was developed from a 90-year-old Wistar [WNIN] inbred rat stock colony maintained at National Institute of Nutrition, India. WNIN/Ob, which arose spontaneously from WNIN in 1997 has homozygous lean $(+/+)$ and obese $(-/-)$ phenotypes. Rats of the obese phenotype are euglycemic and characterized by hyperphagia, hypertriglyceridemia, hypercholesterolemia, hyperleptinemia and hyperinsulinemia [4].

Male, five-month-old 32 lean and 32 obese rats of WNIN/Ob strain were obtained from the National Centre for Laboratory Animal Sciences (NCLAS) and broadly divided into two groups A and B respectively. Each group was further divided into four subgroups (AI, AII, AIII, AIV \& BI, BII, BIII, BIV) consisting of 8 rats each. Subgroups AI and BI received $2.6 \mathrm{mg}$ of vitamin A $/ \mathrm{kg}$ diet and formed the control group. The stock diet consisted of $22.5 \%$ wheat flour, $60 \%$ Bengal-gram flour, $5 \%$ skimmed milk powder, $4 \%$ casein, $4 \%$ salt mixture and $0.5 \%$ vitamin mixture. The animals were provided with powdered chow of standard composition established at our institute containing all the recommended macro and micronutrients (56\% carbohydrate, $18.5 \%$ protein, $8 \%$ fat, $12 \%$ fiber and adequate levels of minerals and vitamins) needed for rats. Subgroups AII and BII received $26 \mathrm{mg}$, subgroups AIII and BIII received $52 \mathrm{mg}$, while subgroups AIV and BIV received $129 \mathrm{mg}$ of vitamin A / kg diet; as retinyl palmitate (a generous gift from Nicholas Piramal India Ltd.) respectively. All diets were identical with regard to all other ingredients except vitamin A content. Rats were housed individually with an ambient temperature $22.0 \pm 1{ }^{\circ} \mathrm{C}$, relative humidity of $50-60 \%$, 12-h:12-h lightdark cycle and fed their respective diets for a period of 20 weeks. At the end of experimental feeding, the animals were fasted in the evening for 12-h and the next day morning blood was collected from supra-orbital sinus via the inner canthus, and plasma samples were prepared. Later the animals were sacrificed by $\mathrm{CO}_{2}$ asphyxiation and various adipose tissues were excised in their entirety, weighed, frozen in liquid nitrogen, and stored at $-80^{\circ} \mathrm{C}$ for further analysis. Animal experiment was approved by Institutional Animal Ethical Committee and conducted in accordance with the principle of the guide to the care and use of experimental animals.

\section{Body composition analysis by total body electrical conductivity}

Two days prior to experimental sacrifice, total body composition was analyzed by small animal body composition analyzer (EM-SCAN, Model SA-3000 Multidetector, Springfield, USA) using Total Body Electrical Conductivity (TOBEC) method as described earlier [6]. This instrument measures total body electrical conductivity of small animals in a non-invasive manner. The rats were anaesthetized lightly with ether and placed in a carrier in the TOBEC chamber and 10 to 12 recordings were taken. The intra-assay coefficient of variation was less than $3.0 \%$. In lean rats the estimation was carried out using coil with I.D. 3076 and in obese rats by coil with I.D. 3011. The following body composition parameters were obtained mathematically, where E stands for total electrical conductivity:

1. Lean body mass $=0.5 \mathrm{E}+(0.3 \times$ total body weight $)$

2. Total body fat $=$ total body weight - lean body mass

3. Total body fat percent $=$ (total body fat $/$ total body weight) $\times 100$

4. Fat - free mass $=16.28+0.4 \mathrm{E}$

\section{Body temperature measurement}

Body temperature was measured as rectal temperature by using BIO-pac MP-100 polygraph (Stoleting group of companies, CA, USA).

\section{Biochemical parameters}

Serum and tissue retinol levels were determined by high-performance liquid chromatography as described previously [4]. Briefly, $100 \mu \mathrm{l}$ of retinyl acetate (internal standard; $1 \mu \mathrm{g} / \mathrm{mL}$ ) was added to $100 \mu \mathrm{l}$ of serum and vortexed for $10-20$ seconds. Hexane $(120 \mu \mathrm{l})$ was added and contents were vigorously mixed but intermittently for 4 seconds, making sure that the bottom layer was 
thoroughly extracted. The tubes were centrifuged at $2200 \mathrm{rpm}$ for 5 minutes and the upper hexane layer was carefully transferred to a fresh tube, evaporated under a stream of nitrogen and immediately reconstituted in methanol and injected for analysis by highperformance liquid chromatography (Shimadzu LC-6A model, Kyoto, Japan).

Liver and retroperitoneal white adipose tissue (WAT) were first washed free of blood, blotted and weighed. The tissues were then ground well with anhydrous sodium sulfate (thrice its weight) till a dry powder was obtained. About $100 \mathrm{mg}$ of dry liver powder and $200 \mathrm{mg}$ of dry retroperitoneal WAT powder was taken and extracted in $25 \mathrm{~mL}$ of diethyl ether and left overnight with occasional gentle shaking at $4^{\circ} \mathrm{C}$. $500 \mu \mathrm{l}$ of the ether extract was evaporated under a stream of nitrogen and reconstituted in methanol and injected for analysis by high-performance liquid chromatography.

\section{Transmission electron microscopy}

Brown adipose tissue (BAT) was fixed by immersion in the Karnovsky fixative overnight at $4^{\circ} \mathrm{C}$, dehydrated, cleared, and then resin-embedded. 600-900 $\mathrm{A}^{0}$ thick sections were obtained and stained with uranyl citrate and lead citrate (Taab laboratories, UK) and scanned using transmission electron microscope (Hitachi, H-7500, Japan) at 60-80 KV to assess morphology [7]. Photomicrographs were taken at $15000 \mathrm{x}$ magnification.

\section{DNA fragmentation analysis}

Epididymal white adipose tissue (eWAT) DNA was isolated and analyzed for fragmentation as per the method of Gullicksen PS et al. [8]. $200 \mathrm{mg}$ of tissue was homogenized in $1 \mathrm{~mL}$ of lysis buffer $(10 \mathrm{mM}$ Tris- $\mathrm{HCl} \mathrm{pH} \mathrm{8.0,}$ $10 \mathrm{mM}$ EDTA and $0.5 \%$ triton X-100) and centrifuged at $14,000 \times \mathrm{g}$ for 15 minutes at $4^{\circ} \mathrm{C}$. The supernatant containing soluble (fragmented) DNA was transferred to a new tube. DNAzol (MRC, Cincinnati, USA) (0.5 ml) was added to the pellet containing insoluble (genomic) DNA. Both tubes were treated with RNase A $(0.5 \mathrm{mg} / \mathrm{ml})$ for 30 minutes at $37^{\circ} \mathrm{C}$. Equal volumes of phenol/chloroform/ isoamyl alcohol were added to the soluble DNA fraction, vortexed and centrifuged at $16,000 \times \mathrm{g}$ for 10 minutes at room temperature. The aqueous phase was collected and $5 \mu \mathrm{l}$ of $\mathrm{MgCl}_{2}$ (<10 mM final conc.) and $1 / 2 \mathrm{vol}$ of $7.5 \mathrm{M}$ ammonium acetate were added and then mixed by inversion. The DNA was precipitated by addition of an equal volume of isopropyl alcohol. The samples were mixed and stored for 1 hour at $-20^{\circ} \mathrm{C}$. The DNA precipitate was pelleted by centrifugation at $10,000 \times \mathrm{g}$ for 30 minutes, and washed twice with $1 \mathrm{ml} \mathrm{70 \%} \mathrm{ethanol}$ followed by centrifugation at $10,000 \times \mathrm{g}$ for 3 minutes.

The genomic DNA fraction containing DNAzol was centrifuged at $16,000 \times \mathrm{g}$ for 3 minutes to sediment insoluble material. The supernatant was collected and DNA was precipitated by the addition of $1 / 2 \mathrm{vol}$ of ethanol, mixed and stored for 3 minutes at room temperature. The DNA precipitate was sedimented by centrifugation at $10,000 \times \mathrm{g}$ for 5 minutes, and washed twice with $1 \mathrm{ml}$ of $70 \%$ ethanol and centrifuged at $5,000 \times \mathrm{g}$ for 3 minutes. The DNA pellets from both fractions were air-dried and resolubilized in $25 \mu \mathrm{l}$ TrisEDTA buffer ( $\mathrm{pH}$ 8.0). Soluble DNA $(10 \mu \mathrm{l})$ and genomic DNA $(5 \mu \mathrm{l})$ was loaded onto a $2 \%$ agarose gel, which was stained with ethidium bromide and visualized with UV light (DSS imagetech imager, India).

\section{Western blot analysis}

BAT samples were homogenized in a buffer containing $250 \mathrm{mM}$ sucrose, $10 \mathrm{mM}$ HEPES $\mathrm{pH}$ 3.5, $0.5 \mathrm{mM}$ EDTA, $0.1 \%$ BSA supplemented with $5 \%$ protease inhibitor cocktail and obtained various cellular fractions by differential centrifugation. Nuclear fraction was used to detect retinoic acid receptor $\alpha(\mathrm{RAR} \alpha)$ and rexinoid receptor $\alpha(R X R \alpha)$, using rabbit polyclonal antibodies (Santa Cruz Biotechnology, CA, USA), while uncoupling protein 1 (UCP1) protein levels were detected in mitochondrial fraction using polyclonal goat anti-UCP1 antibody (Santa Cruz Biotechnology, CA, USA). Immunoblotting of $\mathrm{Bcl} 2$ and $\mathrm{Bax}$ in eWAT was done as described previously [9] using polyclonal anti-bcl2 and anti-bax antibodies (Imgenex, CA, USA). Equal loading of the protein and transfer were ensured by staining the membrane with Ponceau S. Immuno-reactive proteins were detected by ECL advance western blotting detection kit (GE Healthcare, UK) and band density was analyzed by using quantity one software (GS-710 Imaging Densitometer- Bio-Rad, Hercules, CA, USA).

\section{Statistical analysis}

Data are presented as mean \pm SE. Differences among the various groups were assessed by one-way ANOVA; contrast between means was assessed by least-significance difference (LSD) post-hoc comparison. Statistical significance was determined at $P<0.05$. The analyses were performed with SPSS 11.0 for windows (SPSS, Chicago, IL).

\section{Results}

\section{Effects of vitamin A supplementation on biometric parameters}

The effects of vitamin A supplementation on biometric parameters are shown in Table 1 . There was a reduction in the body weight gain, total body fat and fat $\%$ without affecting food intake in vitamin A fed-obese rats (BIII \& BIV respectively) receiving 52 and $129 \mathrm{mg} / \mathrm{kg}$ diet, while no such changes were observed in obese rats fed on $26 \mathrm{mg}$ of vitamin $\mathrm{A} / \mathrm{kg}$ diet (BII) as against the control diet-fed obese rats $(\mathrm{BI})$. Obese rats receiving $52 \mathrm{mg}$ of 
Table 1 Effects of vitamin A supplementation on biometric parameters in WNIN/Ob rats

\begin{tabular}{|c|c|c|c|c|c|c|c|c|}
\hline \multirow{2}{*}{ Parameters } & \multicolumn{4}{|c|}{ Lean } & \multicolumn{4}{|c|}{ Obese } \\
\hline & $\overline{\mathrm{Al}}$ & All & Alll & AIV & $\overline{\mathrm{BI}}$ & BII & BIII & BIV \\
\hline Initial body wt. (g) & $352 \pm 13.3^{a}$ & $374 \pm 8.2^{a}$ & $351 \pm 21.8^{a}$ & $362 \pm 24.9^{a}$ & $628 \pm 48.3^{b}$ & $594 \pm 36.4^{b}$ & $574 \pm 27.9^{b}$ & $591 \pm 12.9^{b}$ \\
\hline Final body wt. (g) & $424 \pm 19.8^{a}$ & $455 \pm 7.1^{a}$ & $441 \pm 19.2^{a}$ & $454 \pm 13.3^{a}$ & $926 \pm 56.2^{b}$ & $883 \pm 38.9^{b c}$ & $811 \pm 33.4^{c d}$ & $778 \pm 23.8^{d}$ \\
\hline Body wt. gain (g) & $72 \pm 18.9^{a}$ & $80 \pm 10.1^{a}$ & $90 \pm 25.1^{a}$ & $92 \pm 15.9^{a}$ & $298 \pm 22.1^{b}$ & $288 \pm 10.9^{b c}$ & $237 \pm 20.8^{c d}$ & $189 \pm 17.2^{d}$ \\
\hline Food intake (g/day) & $18.9 \pm 0.57^{a}$ & $17.4 \pm 0.68^{a}$ & $19.4 \pm 2.15^{a}$ & $18.8 \pm 0.86^{a}$ & $27.9 \pm 0.82^{b}$ & $29.3 \pm 1.06^{b}$ & $28.1 \pm 1.33^{b}$ & $26.8 \pm 0.60^{b}$ \\
\hline Lean body mass (g) & $361 \pm 14.9^{a}$ & $398 \pm 8.3^{a}$ & $389 \pm 15.0^{a}$ & $402 \pm 11.1^{a}$ & $410 \pm 26.9^{a}$ & $399 \pm 17.6^{a}$ & $376 \pm 15.1^{a}$ & $362 \pm 9.1^{a}$ \\
\hline Total body fat (g) & $63 \pm 5.6^{a}$ & $57 \pm 3.2^{a}$ & $52 \pm 5.6^{a}$ & $52 \pm 4.8^{a}$ & $516 \pm 30.8^{b}$ & $481 \pm 15.5^{b}$ & $435 \pm 18.5^{c}$ & $416 \pm 15.3^{c}$ \\
\hline Fat\%* & $14.6 \pm 0.75^{a}$ & $12.6 \pm 0.77^{b}$ & $11.7 \pm 0.90^{b}$ & $11.4 \pm 0.84^{b}$ & $55.8 \pm 0.69^{c}$ & $54.7 \pm 0.40^{c d}$ & $53.7 \pm 0.22^{d}$ & $53.4 \pm 0.44^{d}$ \\
\hline IWAT $\varphi$ & $1.2 \pm 0.07^{a}$ & $1.3 \pm 0.23^{a}$ & $1.1 \pm 0.19^{a}$ & $1.5 \pm 0.19^{a}$ & $9.4 \pm 1.02^{b}$ & $8.1 \pm 0.19^{b d}$ & $7.6 \pm 1.22^{c d}$ & $6.4 \pm 0.45^{c}$ \\
\hline eWAT ${ }^{@}$ & $0.8 \pm 0.22^{a c}$ & $0.7 \pm 0.06^{a c}$ & $0.6 \pm 0.05^{a c}$ & $0.7 \pm 0.08^{a c}$ & $1.5 \pm 0.26^{b}$ & $1.4 \pm 0.35^{b d}$ & $0.9 \pm 0.08^{c d}$ & $1.0 \pm 0.12^{a b c}$ \\
\hline Rectal temperature $\left({ }^{\circ} \mathrm{C}\right)$ & $37.6 \pm 0.03^{a e}$ & $37.6 \pm 0.31^{a e}$ & $37.6 \pm 0.31^{a e}$ & $37.6 \pm 0.22^{a e}$ & $36.0 \pm 0.19^{b}$ & $37.7 \pm 0.18^{a}$ & $38.3 \pm 0.21^{c d}$ & $37.7 \pm 0.12^{c e}$ \\
\hline
\end{tabular}

Five-month-old male lean (A) and obese (B) rats were fed vitamin A at a dose of 2.6 (I), 26 (II), 52 (III) and 129 (IV) mg/kg diet for a period of 20 weeks. Al served as the control group for lean phenotype, while BI was control group for obese phenotype. Data are mean $\pm S E$ ( $n=8$ for $A$, All, Alll, AIV; $n=7$ for $B I, B I I, B I V ; n=6$ for BIII). LBM, lean body mass; FAT\%, fat percentage; eWAT, epididymal WAT; rWAT, retroperitoneal WAT.

a-e Mean values within a row not sharing a common superscript were significantly different by oneway ANOVA and LSD post hoc comparison $(P<0.05)$. ${ }^{*}$ Total body fat expressed as a percentage of body weight. MMass of rWAT expressed as a percentage of body weight. @Mass of eWAT expressed as a percentage of body weight.

vitamin $\mathrm{A} / \mathrm{kg}$ diet showed a significant reduction in both retroperitoneal white adipose tissue (rWAT) and eWAT, while the diet providing $129 \mathrm{mg}$ of vitamin A/kg diet showed a reduction in rWAT alone. Further, the omental and brown adipose tissue weights remained unaltered upon feeding vitamin A-enriched diets (data not shown). Obese rats $(\mathrm{BI})$ displayed lower rectal temperature than lean rats fed on control-diet (AI), which increased significantly upon vitamin A feeding. Except decreased fat $\%$, no other changes in body composition, mass of various fat depots, food intake and rectal temperature were seen in identically-treated lean rats, as compared to control diet-fed lean rats (AI).

\section{Effect of vitamin A supplementation on retinol levels} Obese rats (BI) had higher serum retinol levels than their age and sex-matched lean counterparts fed on control diet (AI). Circulating retinol levels were not significantly affected by feeding vitamin A-enriched diets in both phenotypes. Total retinol levels in liver and rWAT were lower in obese control rats (BI) compared to their lean counterparts (AI). Significant increase in total retinol levels were seen in the liver (with all doses of vitamin A) and rWAT (with doses 52 and $129 \mathrm{mg}$ of vitamin $\mathrm{A} / \mathrm{kg}$ diet) of both lean and obese rats, when compared to their respective control diet-fed rats (Table 2).

\section{Effect of vitamin A supplementation on BAT UCP1, RARa and RXRa expression}

Obese control rats (BI) showed an under-expression of BAT-UCP1 protein as compared to their age and sexmatched lean rats (AI). UCP1protein levels significantly increased after feeding vitamin A supplemented diets (26 and $52 \mathrm{mg} / \mathrm{kg}$ diet) when compared with control diet-fed obese rats (BI); the effect was maximal (2.5 fold) at a dose of $52 \mathrm{mg} / \mathrm{kg}$ diet and diminished at $129 \mathrm{mg} / \mathrm{kg}$ diet. Though, UCP1 protein levels were increased by vitamin A supplementation in lean rats; they were not statistically significant (Figure 1).

Basal expression of BAT nuclear receptors- RAR $\alpha$ and $\mathrm{RXR} \alpha$ protein levels were comparable between control diet-fed lean (AI) and obese rats (BI). Compared to control diet group (BI), vitamin A supplementation to obese rats decreased RAR $\alpha$ levels at all doses. Interestingly, in obese

Table 2 Effects of vitamin A supplementation on retinol levels in WNIN/Ob rats

\begin{tabular}{|c|c|c|c|c|c|c|c|c|}
\hline \multirow{2}{*}{ Parameters } & \multicolumn{4}{|c|}{ Lean } & \multicolumn{4}{|c|}{ Obese } \\
\hline & $\mathrm{Al}$ & All & Alll & AIV & $\mathrm{BI}$ & BII & BIII & BIV \\
\hline Serum retinol $(\mu \mathrm{g} / \mathrm{dL})$ & $28 \pm 1.4^{a}$ & $28 \pm 1.3^{a}$ & $26 \pm 2.0^{a}$ & $29 \pm 3.4^{a}$ & $40 \pm 1.6^{b}$ & $41 \pm 2.5^{b}$ & $46 \pm 3.9^{b}$ & $43 \pm 5.7^{b}$ \\
\hline Liver retinol ( $\mu \mathrm{g} / \mathrm{g}$ tissue) & $967 \pm 386^{a}$ & $3795 \pm 211^{b c}$ & $4556 \pm 465^{b c}$ & $9842 \pm 1151^{d}$ & $375 \pm 60^{a}$ & $2840 \pm 221^{b}$ & $5031 \pm 239^{c}$ & $8133 \pm 883^{d}$ \\
\hline rWAT retinol ( $\mu \mathrm{g} / \mathrm{g}$ tissue) & $4 \pm 1.2^{a c}$ & $14 \pm 3.0^{\text {ade }}$ & $19 \pm 1.5^{d e}$ & $41 \pm 7.7^{b}$ & $2 \pm 0.3^{c}$ & $11 \pm 0.9^{a c d}$ & $24 \pm 3.4^{e}$ & $48 \pm 5.6^{b}$ \\
\hline
\end{tabular}

Five-month-old male lean (A) and obese (B) rats were fed vitamin A at a dose of 2.6 (I), 26 (II), 52 (III) and 129 (IV) mg/kg diet for a period of 20 weeks. Al served as the control group for lean phenotype, while BI was control group for obese phenotype. Data are mean \pm SE ( $n=8$ for Al, All, All, AIV; $n=7$ for BI, Bll, BIV; $n=6$ for BIII). rWAT, retroperitoneal WAT.

a-e Mean values within a row not sharing a common superscript were significantly different by oneway.

ANOVA and LSD post hoc comparison $(P<0.05)$. 

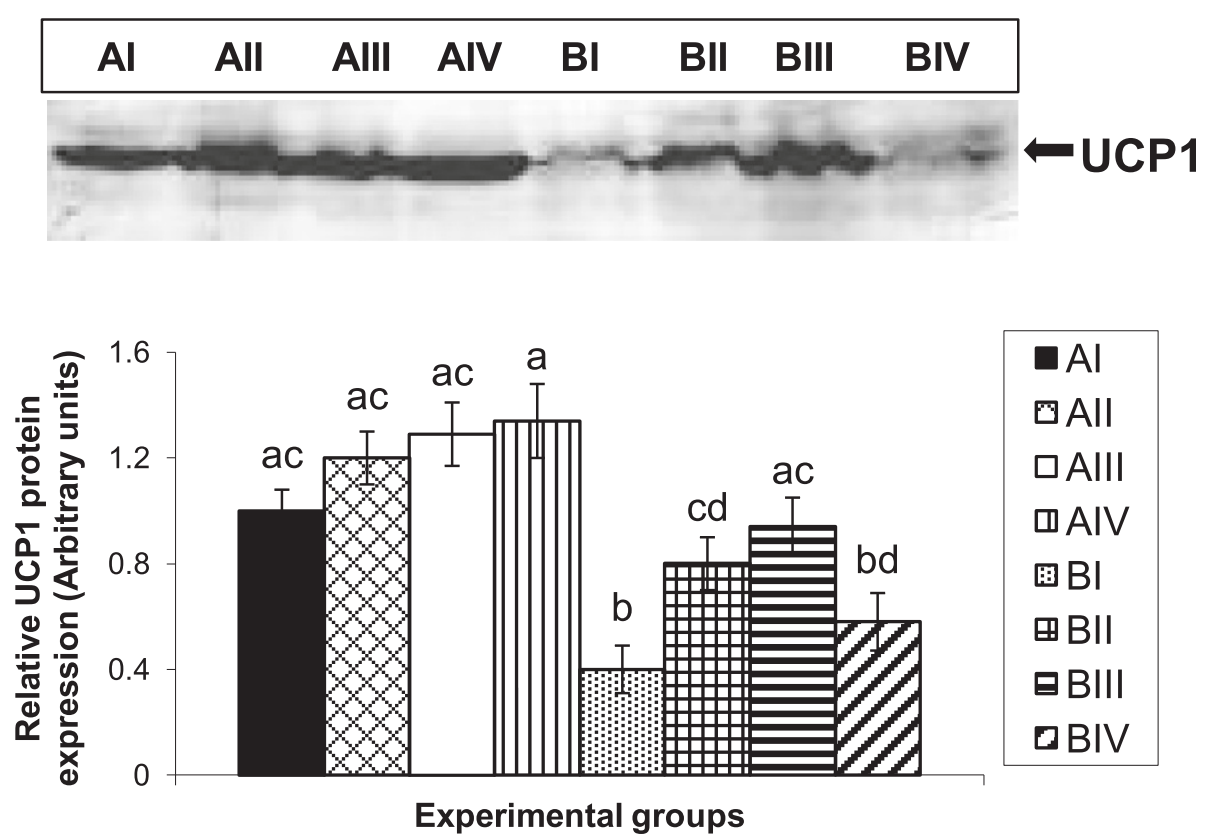

\begin{tabular}{|c|}
\hline $\mathrm{Al}$ \\
\hline OAll \\
\hline$\square$ Alll \\
\hline ФAIV \\
\hline 田 BI \\
\hline 田BII \\
\hline घBIII \\
\hline DBIV \\
\hline
\end{tabular}

(Effect of vitamin A supplementation on BAT-UCP1 protein levels in lean and obese rats. Five-month-old male lean (A) and obese (B) rats were fed vitamin A at a dose of 2.6 (I), 26 (II), 52 (III) and 129 (IV) mg/kg diet for a period of 20 weeks. Representative western blot showing the levels of UCP1 in BAT of lean and obese rats supplemented with various doses of vitamin A. Equal loading of the protein was ensured by staining the membranes with Ponceau S (image not shown). Bar graph shows the densitometric analysis of 3 rats, representing each of the dietary group. Bars are mean \pm SE and are expressed relative to the mean value of lean control group (Al), which was set as 1. ${ }^{a-d}$ Bars not sharing a common superscript are significantly different by one-way ANOVA and LSD post hoc comparison $(P<0.05)$.

rats RXR $\alpha$ expression decreased upon feeding with 26 and $52 \mathrm{mg}$ of vitamin $\mathrm{A} / \mathrm{kg}$ diet (BII and BIII respectively), while increased levels were observed with dose of $129 \mathrm{mg} /$ $\mathrm{kg}$ diet (BIV) as compared to control diet- fed obese rats (BI). In contrast, no changes were observed in RAR $\alpha$ and $\mathrm{RXR} \alpha$ levels in lean rats fed vitamin A-enriched diets (Figure 2).

Effect of vitamin A supplementation on BAT morphology We conducted a morphological study, wherein BAT sections of control and vitamin A-supplemented lean and obese rats were examined by electron microscopy for possible differences. Transmission electron microscopic (TEM) analysis of BAT revealed that control obese rats (BI) had relatively less number of mitochondria and also ruptured mitochondrial membranes as compared to their lean counterparts $(\mathrm{AI})$ in a given field. Feeding of 26 and $52 \mathrm{mg}$ of vitamin $\mathrm{A} / \mathrm{kg}$ diet to obese rats (BII \& BIII respectively) triggered an increase in the number of intact mitochondria, while no such changes were observed in obese rats (BIV) receiving $129 \mathrm{mg}$ of vitamin $\mathrm{A} / \mathrm{kg}$ diet as compared to control diet-fed obese rats (BI). Vitamin A supplementation (52 and $129 \mathrm{mg} / \mathrm{kg}$ diet) in lean rats also resulted in increased number of mitochondria as compared to the control diet-fed lean rats (AI) (Figure 3).
Effect of vitamin A supplementation on Bcl2 and Bax expression in epididymal and retroperitoneal WAT

Basal levels of $\mathrm{Bcl} 2$ and Bax were comparable in eWAT of lean (AI) and obese (BI) rats fed on control diet. Compared to control group (BI), Bcl2 and Bax levels significantly decreased and increased respectively in obese rats receiving $52 \mathrm{mg}$ of vitamin $\mathrm{A} / \mathrm{kg}$ diet (BIII) resulting in decreased ratio of $\mathrm{Bcl} 2$ to $\mathrm{Bax}$, but not in other groups fed with either 26 (BII) or $129 \mathrm{mg}$ of vitamin A/kg diet (BIV) (Figure 4). On the other hand, no changes in $\mathrm{Bcl} 2$ and Bax expression levels were observed in lean rats challenged with various doses of vitamin A (Figure 4). Vitamin A supplementation had no effect on $\mathrm{Bcl} 2$ and Bax expression levels in rWAT of both lean and obese rats (data not shown).

\section{Effect of vitamin A supplementation on DNA fragmentation in epididymal WAT}

The decreased $\mathrm{Bcl} 2$ to Bax ratio in eWAT of obese rats fed $52 \mathrm{mg}$ of vitamin $\mathrm{A} / \mathrm{kg}$ diet was, further corroborated with the observed nucleosomal DNA fragmentation in this group. However, the same was not observed in obese rats (BII \& BIV) fed with 26 and $129 \mathrm{mg}$ of vitamin A/kg diet or in lean rats challenged with various doses of vitamin A (Figure 5). 


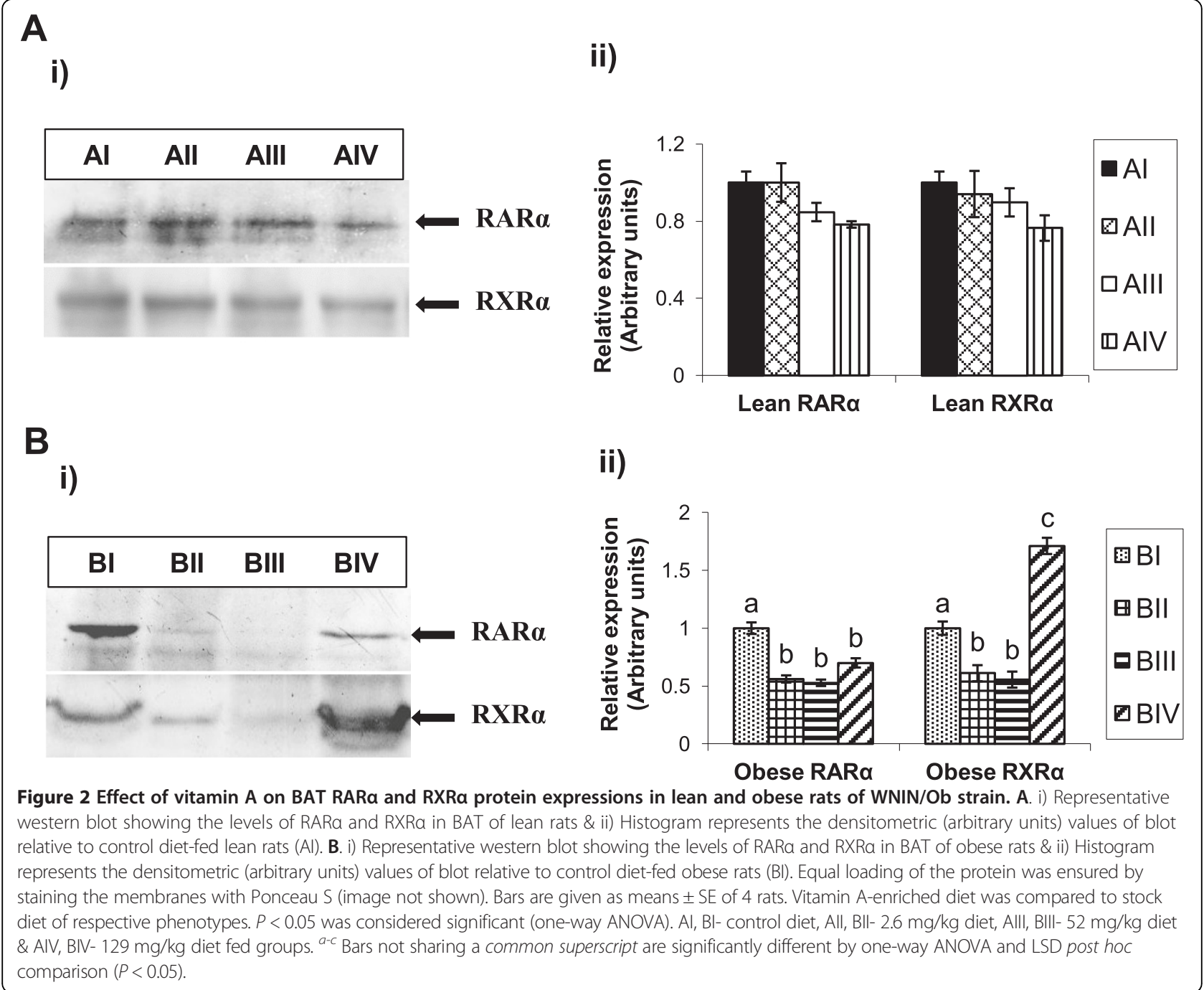

\section{Discussion}

We have shown previously that chronic feeding of vitamin A-enriched diet $(129 \mathrm{mg} / \mathrm{kg}$ diet $)$ to obese rats reduced body weight and adiposity without affecting food intake, possibly due to the activation of thermogenic pathway through up-regulation of the BAT-UCP1 gene (4). In the present study, we observed that the consumption of vitamin A-enriched diet at doses of 52 and $129 \mathrm{mg} / \mathrm{kg}$ diet significantly decreased the gain in body weight, total body fat and retroperitoneal and epididymal WAT of obese rats as compared with their control diet-fed obese counterparts. It is interesting to note that the overall response of vitamin A supplementation was observed in obese but not in lean rats, suggesting possible differences in their vitamin A requirements/metabolism and the role of genetic-make up in eliciting such divergent response. In addition, vitamin A supplementation at any of the doses did not result in decreased food intake or other vitamin A toxicity symptoms. In order to elucidate the detailed mechanism involved in vitamin A-mediated weight reduction, we looked at the expression of thermogenic and apoptotic genes.

UCP1 is a brown-adipocyte-specific marker and the key molecular effector of thermogenesis [10]. Like other models of obesity (ob/ob, db/db mice and fa/fa rats), obese rats of WNIN/Ob strain show impaired BAT thermogenesis, which is associated with low UCP1 levels in BAT [11]. It is very well documented that vitamin $A$ and its active metabolite; retinoic acid (RA) are positive regulators of UCP1. Feeding of vitamin A-deficient diets to rats and mice resulted in reduced BAT-UCP1 expression and increased adiposity, while all trans-RA treatment and vitamin A supplementation caused an increment of BAT thermogenic capacity and reduction of whole body adiposity, compared to their control animals [4,12-15]. In line with these observations, our study also showed a marked induction of BAT-UCP1 expression in obese rats supplemented with 26 and 


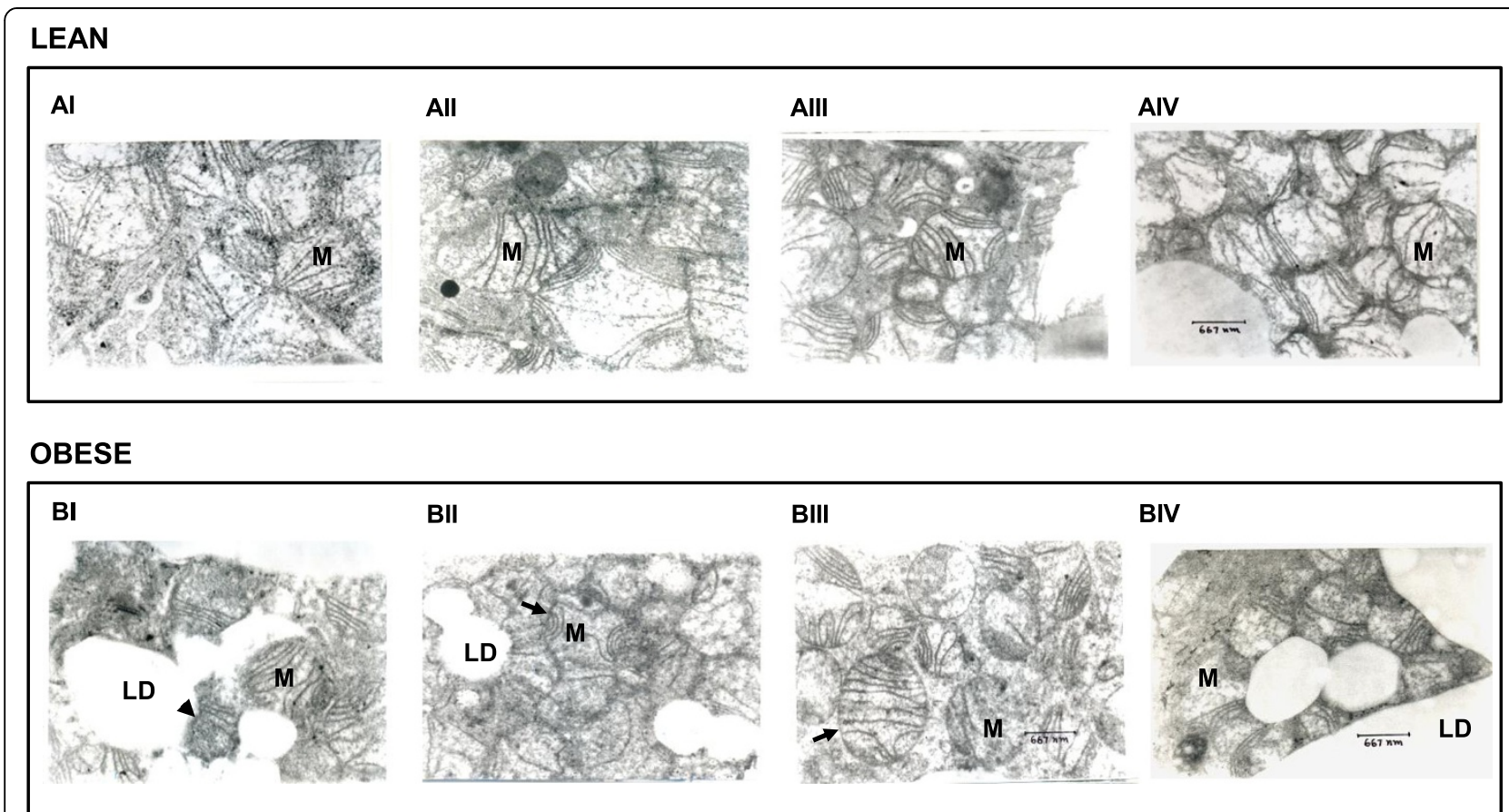

Figure 3 Effect of vitamin A supplementation on BAT morphology. Five-month-old male lean (A) and obese (B) rats were fed vitamin A at a dose of 2.6 (I), 26 (II), 52 (III) and 129 (IV) mg/kg diet for a period of 20 weeks. Al served as the control group for lean phenotype, while BI was the control group for obese phenotype. The BAT samples were fixed, and sections were stained with uranyl citrate and lead citrate for morphologic analysis. Photomicrographs were taken at 15000x magnification. Scale bar, $667 \mathrm{~nm}$. The ruptured membranes observed in obese group (BI) are depicted by arrow heads. The intact mitochondria in BII and BIII are depicted by arrow. M- mitochondria, LD- lipid droplet.

$52 \mathrm{mg}$ of vitamin $\mathrm{A} / \mathrm{kg}$ diet. Increased thermogenesis results in elevated body temperature and, indeed, increased rectal temperature was observed in obese rats supplemented with vitamin A.

The responsiveness of UCP1 to retinoids is majorly mediated by nuclear transcription factors RAR $\alpha$ and RXR $\alpha$ $[15,16]$. Similar to earlier studies reported in both cultured primary brown adipocytes and BAT of mice, our observations also supported the down-regulatory effect of vitamin A in obese rats fed 26 and $52 \mathrm{mg}$ of vitamin A/kg diet on RAR $\alpha$ and, especially RXR $\alpha$ protein levels that paralleled the induction of UCP1, suggesting auto-regulated feedback inhibition of the retinoids on the thermogenic system $[15,16]$. Although, vitamin A is considered as a positive regulator of UCP1 gene expression, a recent study comparing the dose dependent activation of UCP1 in various mouse adipocytes revealed that intermediate concentrations of RA enhance UCP1 expression whereas higher concentrations failed to do so and this effect was mediated by the action of RARs [17]. Similarly, in the present study we observed the absence of UCP1 activation in BAT of obese rats at the highest dose $(129 \mathrm{mg}$ of vitamin $\mathrm{A} / \mathrm{kg}$ diet) which could be due to increased RXR $\alpha$ levels and may be seen as turning-on of inhibitory mechanisms by vitamin A to prevent thermogenic activation. On the other hand, lean rats displayed no significant transcriptional activation of BAT-UCP1 in response to vitamin A-enriched diet, probably, as lean rats already had a maximal basal expression of UCP1.

For the first time, we report that TEM analysis of BAT reveals low number of mitochondria with disrupted membranes in these obese rats, which clearly suggest that not only the mitochondrial number but also the membrane structure is affected by obesity leading to augmented energy deposition as fat. Vitamin A is known to facilitate stable organization of well-developed lamellar cristae of the inner mitochondrial membrane, which is the hallmark of active BAT mitochondria [18]. Vitamin A-induced BAT-UCP1 expression in obese rats was also accompanied by morphological changes, notably, increased number of mitochondria in BAT and this could be conducive for the respiratory activity of the mitochondria and subsequent induction of thermogenic response. Thermogenic activation of BAT by vitamin A, is of practical relevance in the context of recent findings that active BAT depots are found in humans and cold-induced BAT activity is impaired in overweight healthy subjects [19]. Therefore, understanding the pathways that mediate the effect of vitamin A on UCP1 regulation could be essential for the design and implementation of pharmacological strategies 


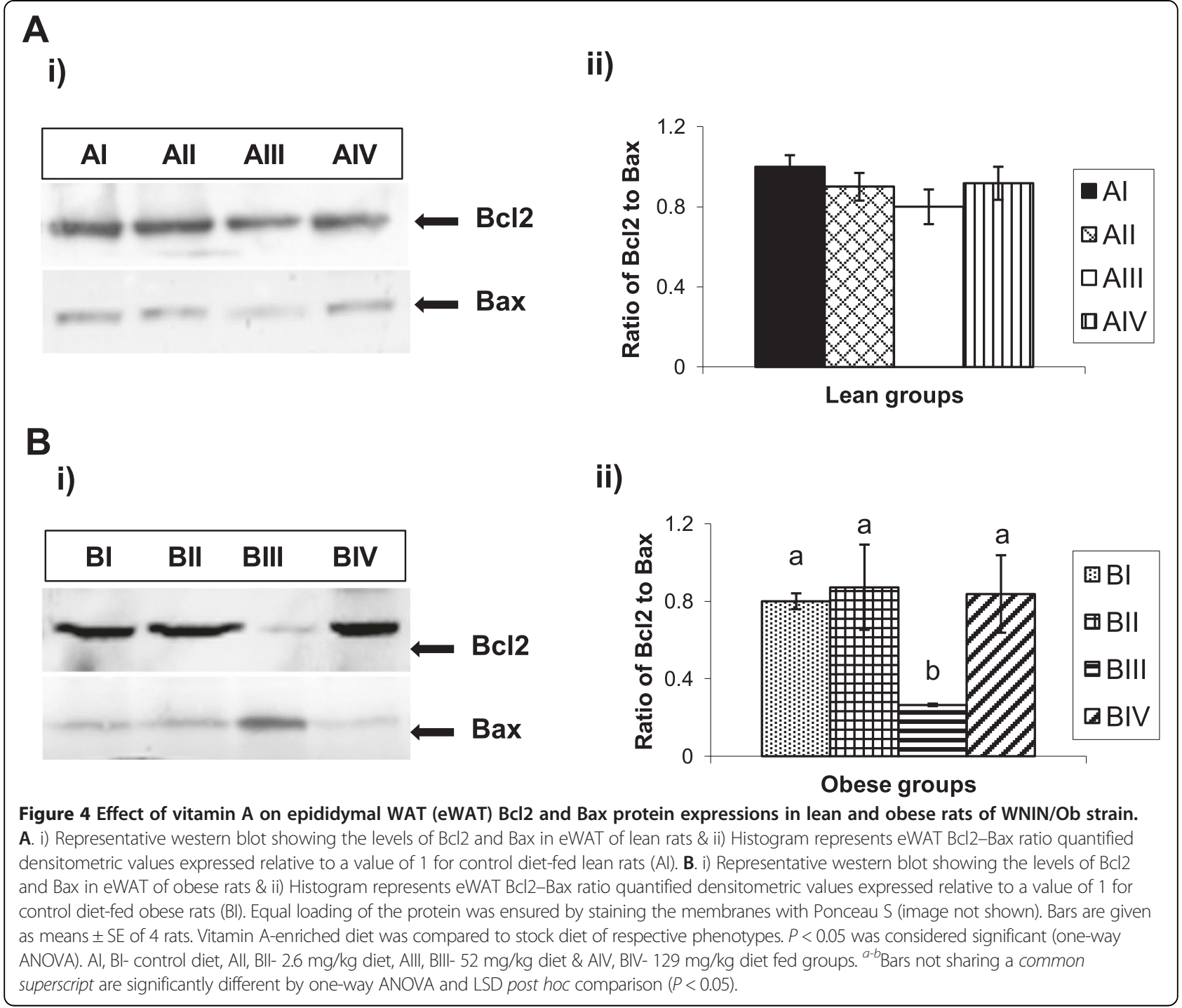

to modulate thermogenic activation and increased energy expenditure.

In our study, we did not find any changes in the plasma retinol levels in response to supplementation with varied vitamin A contents of the diet. Furthermore, the data on liver retinol contents of lean and obese phenotypes suggest that hepatic storage of retinol could be the regulatory mechanism involved in plasma vitamin A homeostasis. Liver contains $66-75 \%$ of the body's total retinol and is the major organ involved in the retinol storage and homeostasis. Next to liver, adipose tissue accounts for $15-20 \%$ of the total body retinoid stores and plays an active role in retinoid homeostasis and metabolism. Our observation, with regard to low liver and retroperitoneal WAT retinol stores, despite higher food intake, is suggestive of low uptake by these tissues or defective intestinal absorption of retinol in obese rats, as compared to lean rats. However, feeding various doses of vitamin A to obese rats raised hepatic and retroperitoneal WAT retinol levels comparable to those observed in lean rats on identical dietary regimen.

Adipose tissue mass is determined by the volume and/ or the number of adipocytes, the former being regulated by lipolytic process and the latter by pre-adipocyte recruitment, differentiation and adipocyte apoptosis [20]. Various studies have substantiated the concept that adipocyte deletion by apoptosis contributes to ablation of adipose tissue and its loss during weight reduction [21-23]. All-trans-RA is known to induce differentiation and subsequent apoptosis in a variety of cell lines by modulating $\mathrm{Bcl} 2$ and $\mathrm{Bax}$ expressions. $\mathrm{Bcl} 2$ and $\mathrm{Bax}$ are prominent regulators of apoptosis, the former helps in prolonging cell survival and the latter antagonizes the function of $\mathrm{Bcl} 2$ and enhances the cellular susceptibility to apoptosis $[24,25]$. Thus, the ratio of $\mathrm{Bcl} 2$ to $\mathrm{Bax}$ is 


\section{A eWAT Genomic DNA}

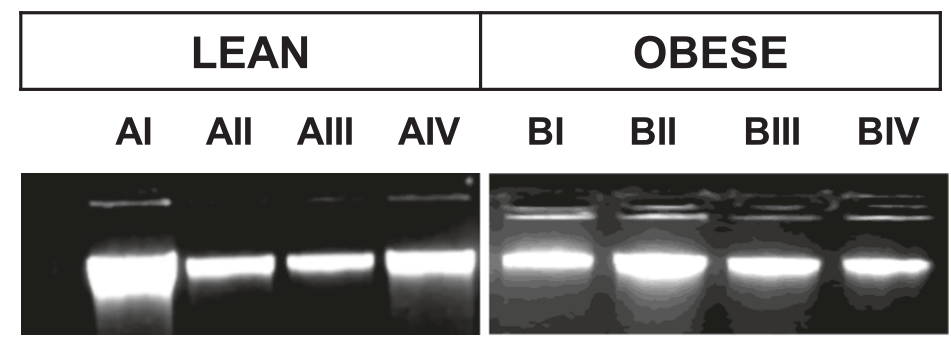

B eWAT Fragmented DNA

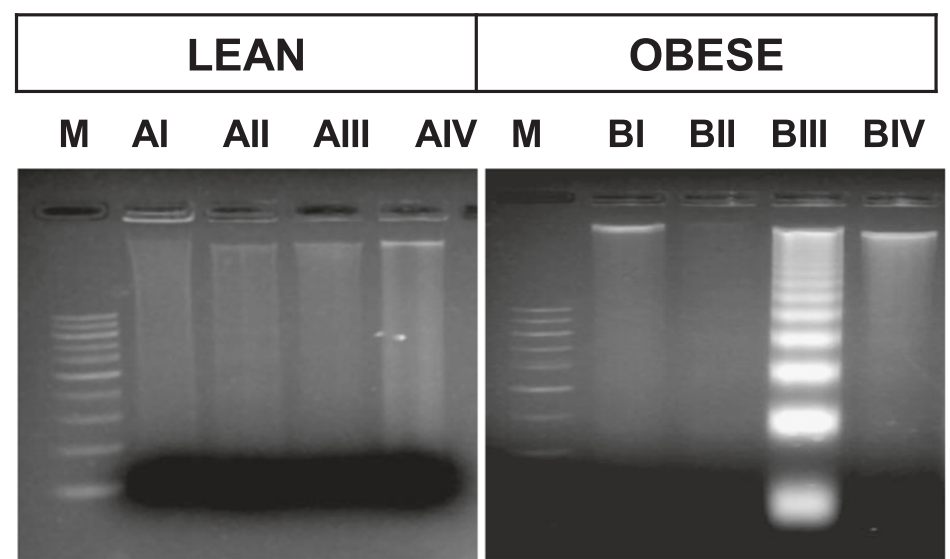

Figure 5 Nucleosomal DNA fragmentation. Representative picture of genomic DNA (A) and fragmented DNA (B) run on an agarose gel stained with ethidium bromide. M - DNA marker containing $100 \mathrm{bp}$ ladder, Al and BI - lean and obese rats respectively fed on 2.6 mg of vitamin A/kg diet, All and BII - lean and obese rats respectively fed on $26 \mathrm{mg}$ of vitamin A/kg diet, Alll and BIII - lean and obese rats respectively fed on $52 \mathrm{mg}$ of vitamin A/kg diet, AIV and BIV - lean and obese rats respectively fed on $129 \mathrm{mg}$ of vitamin A/kg diet.

deemed important in determining cell survival or death. The present study also demonstrates that vitamin A supplementation at a dose of $52 \mathrm{mg} / \mathrm{kg}$ diet induced apoptosis in the epididymal WAT of obese rats by decreasing $\mathrm{Bcl} 2$ and enhancing Bax expressions leading to decreased $\mathrm{Bcl} 2$ to Bax ratio and increasing nucleosomal DNA fragmentation, indicating that the decreased epididymal WAT in these rats is due to increased apoptosis.

It is interesting to note that obese rats fed on $26 \mathrm{mg}$ of vitamin A/ $\mathrm{kg}$ diet had unaltered total body fat (despite increased UCP1 expression), which could be probably due to marginally increased food intake in this group. Surprisingly, high vitamin A treatment of obese rats had no effect on any of the parameters analyzed (BAT-mitochondriogenesis and UCP1 expression, epididymal WAT Bcl2 and Bax expressions). This rules out the possible role of vitamin A-mediated thermogenesis and apoptosis in lowering adiposity in obese rats fed $129 \mathrm{mg}$ of vitamin $\mathrm{A} / \mathrm{kg}$ diet, thereby implicating the role of preadipocyte recruitment and differentiation. In fact, lipoprotein lipase (LPL) and glycerol 3-phosphate dehydrogenase (GPDH) activities, markers of adipocyte differentiation, were found to be markedly elevated in control obese rats as compared with their lean counterparts. Further, high vitamin A supplementation (129 mg/kg diet) resulted in significant decrease in LPL and GPDH activities in obese rats, but not in the lean phenotype (data not shown). Therefore, the observed decrease in the retroperitoneal adipose tissue mass, adiposity and body weight in obese rats supplemented with $129 \mathrm{mg}$ of vitamin A/ $\mathrm{kg}$ diet could be attributed to inhibition of lipogenesis, due to decreased LPL and GPDH activities.

\section{Conclusions}

The present study has clearly established the role of various doses of vitamin A in regulating obesity, using WNIN/Ob obese rats. Vitamin A supplementation at the dose of $52 \mathrm{mg} / \mathrm{kg}$ diet proved to be effective in bringing about a 
reduction in body weight and adiposity in obese rats by enhancing BAT thermogenic activity and inducing apoptosis in epididymal WAT. More importantly, increased understanding of the mechanisms and effectors involved in body weight regulation and their modulation by nutrients can contribute to novel pharmacological/dietary interventions for prevention and treatment of obesity.

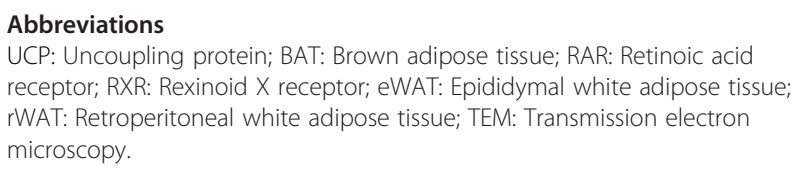

\section{Competing interests}

The authors declare that they have no competing interests.

\section{Authors' contributions}

PA-conduct the animal experiment, research data, analysis, manuscript writing. SMJ-research data, manuscript reviewing and editing. LS-Transmission electron microscopy analysis. NH-Body composition analysis by TOBEC. NVG-Provided experimental animals for the study. AV-Responsible for the study design, funding, analysis, manuscript reviewing and editing. All authors read and approved the final manuscript.

\section{Acknowledgements}

We thank Dr. B. Sesikeran, former Director, NIN, for the keen interest in the study. We thank Mr. P. Madhusudhanachary for assistance in transmission electron microscopic analysis. We also acknowledge the Nicholas Piramal India Ltd, for the generous gift of retinyl palmitate for our study. A. Prashanth is thankful to ICMR for granting the research fellowship.

\section{Author details}

'Department of Lipid Biochemistry, National Institute of Nutrition (ICMR), Jamai Osmania, Hyderabad -500 007, Andhra Pradesh, India. ${ }^{2}$ Ultra Structure Unit, National Institute of Nutrition (ICMR), Jamai Osmania, Hyderabad -500 007, Andhra Pradesh, India. ${ }^{3}$ National Center for Laboratory Animal Sciences (ICMR), Jamai-Osmania, Hyderabad 500 007, Andhra Pradesh, India.

Received: 3 June 2014 Accepted: 11 September 2014

Published: 25 September 2014

\section{References}

1. Cho KJ, Moon HE, Moini H, Packer L, Yoon DY, Chung AS: a-Lipoic acid inhibits adipocyte differentiation by regulating proadipogenic transcription factors via mitogen-activated protein kinase pathways. J Bio Chem 2003, 278:34823-34833.

2. Palou A, Serra F, Bonet ML, Picó C: Obesity: molecular bases of a multi-factorial problem. Eur J Nutr 2000, 39:127-144

3. Prins JB, O'Rahilly $\mathrm{S}$ : Regulation of adipose cell number in man. Clin Sci 1997, 92:3-11.

4. Jeyakumar SM, Vajreswari A, Giridharan NV: Chronic dietary vitamin A supplementation regulates obesity in an obese mutant WNIN/Ob rat model. Obesity 2006, 14:52-59.

5. Jeyakumar SM, Vajreswari A, Giridharan NV: Vitamin A regulates obesity in WNIN/Ob obese rat independent of stearoyl-CoA desaturase-1. Biochem Biophys Res Commun 2008, 370:243-247.

6. Harishankar N, Vajreswari A, Giridharan NV: WNIN/GR-Ob - an insulin-resistant obese rat model from inbred WNIN strain. Indian J Med Res 2011, 134:320-329.

7. Srigiridhar K, Nair KM, Subramanian R, Singotamu L: Oral repletion of iron induces free radical mediated alterations in the gastrointestinal tract of rat. Mol Cell Biochem 2001, 219:91-98.

8. Gullicksen PS, Hausman DB, Dean RG, Hartzell DL, Baile CA: Adipose tissue cellularity and apoptosis after intracerebroventricular injections of leptin and 21 days of recovery in rats. Int J Obes Relat Metab Disord 2003, 27:302-312.

9. Jeyakumar SM, Vajreswari A, Sesikeran B, Giridharan NV: Vitamin A supplementation induces adipose tissue loss through poptosis in lean but not in obese rats of the WNIN/Ob strain. J Mol Endocrinol 2005, 35:391-398.
10. Cannon B, Nedergaard J: Brown adipose tissue: function and physiological significance. Physiol Rev 2004, 84:277-359.

11. Atgié C, Marette A, Desautels M, Tulp O, Bukowiecki L: Specific decrease of mitochondrial thermogenic capacity in brown adipose tissue of obese SHR/N-cp rats. Am J Physiol 1993, 265:C1674-C1680.

12. Kumar MV, Sunvold GD, Scarpace PJ: Dietary vitamin A supplementation in rats: suppression of leptin and induction of UCP1 mRNA. J Lipid Res 1999, 40:824-829.

13. Bonet ML, Oliver J, Picó C, Felipe F, Ribot J, Cinti S, Palou A: Opposite effects of vitamin A deficient diet-feeding and retinoic acid treatment on brown adipose tissue UCP1, UCP2 and leptin expression. J Endocrinol 2000, 166:511-517.

14. Ribot J, Felipe F, Bonet ML, Palou A: Changes of adiposity in response to vitamin A status correlate with changes of PPAR gamma 2 expression. Obes Res 2001, 9:500-509.

15. Ribot J, Felipe F, Bonet ML, Palou A: Retinoic acid administration and vitamin $A$ status modulate retinoid $X$ receptor alpha and retinoic acid receptor alpha levels in mouse brown adipose tissue. Mol Cell Biochem 2004, 266:25-30

16. Bonet ML, Puigserver P, Serra F, Ribot J, Vázquez F, Pico C, Palou A: Retinoic acid modulates retinoid $X$ receptor alpha and retinoic acid receptor alpha levels of cultured brown adipocytes. FEBS Lett 1997, 406:196-200.

17. Murholm M, Isidor MS, Basse AL, Winther S, Sorensen C, Skovgaard-Petersen J, Nielsen MM, Hansen AS, Quistorff B, Hansen JB: Retinoic acid has different effects on UCP1 expression in mouse and human adipocytes. BMC Cell Biol 2013, 14:41.

18. Loncar D: Convertible adipose tissue in mice. Cell Tissue Res 1991, 266:149-161.

19. Van Marken L, Vanhommerig JW, Smulders NM, Drossaerts JM, Kemerink GJ, Bouvy ND, Schrauwen P, Teule GJ: Cold-activated brown adipose tissue in healthy men. N Engl J Med 2009, 360:1500-1508.

20. Bjorntorp P: Adipose tissue distribution and function. Int I Obes Relat Metab Disord 1991, 2:67-81.

21. Ogilvie KM, Saladin R, Nagy TR, Urcan MS, Heyman RA, Leibowitz MD: Activation of the retinoid $\mathrm{X}$ receptor suppresses appetite in the rat. Endocrinology 2004, 145:565-573.

22. Kolonin MG, Saha PK, Chan L, Pasqualini R, Arap W: Reversal of obesity by targeted ablation of adipose tissue. Nat Med 2004, 10:625-632.

23. Hamrick MW, Della-Fera MA, Choi YH, Pennington C, Hartzell D, Baile CA: Leptin treatment induces loss of bone marrow adipocytes and increases bone formation in leptin-deficient ob/ob mice. J Bone Miner Res 2005, 20:994-1001.

24. Murphy KM, Ranganathan V, Farnsworth ML, Kavallaris M, Lock RB: BCl-2 inhibits Bax translocation from cytosol to mitochondria during drug-induced apoptosis of human tumor cells. Cell Death Differ 2000, 7:102-111.

25. Sharpe JC, Arnoult D, Youle RJ: Control of mitochondrial permeability by Bcl-2 family members. Biochim Biophys Acta 2004, 1644:107-113.

doi:10.1186/1743-7075-11-45

Cite this article as: Prashanth et al:: Mitochondriogenesis and apoptosis: possible cause of vitamin A-mediated adipose loss in WNIN/Ob-obese rats. Nutrition \& Metabolism 2014 11:45.

\section{Submit your next manuscript to BioMed Central and take full advantage of:}

- Convenient online submission

- Thorough peer review

- No space constraints or color figure charges

- Immediate publication on acceptance

- Inclusion in PubMed, CAS, Scopus and Google Scholar

- Research which is freely available for redistribution 